\title{
Picture Fuzzy Maclaurin Symmetric Mean Operators and Their Applications in Solving Multiattribute Decision-Making Problems
}

\author{
Kifayat Ullah \\ Department of Mathematics, Riphah Institute of Computing \& Applied Sciences (RICAS), \\ Riphah International University (Lahore Campus), Lahore 54000, Pakistan
}

Correspondence should be addressed to Kifayat Ullah; kifayat.khan.dr@gmail.com

Received 26 July 2021; Revised 2 September 2021; Accepted 7 September 2021; Published 4 October 2021

Academic Editor: Ali Ahmadian

Copyright $(2021$ Kifayat Ullah. This is an open access article distributed under the Creative Commons Attribution License, which permits unrestricted use, distribution, and reproduction in any medium, provided the original work is properly cited.

To evaluate objects under uncertainty, many fuzzy frameworks have been designed and investigated so far. Among them, the frame of picture fuzzy set (PFS) is of considerable significance which can describe the four possible aspects of expert's opinion using a degree of membership (DM), degree of nonmembership (DNM), degree of abstinence (DA), and degree of refusal (DR) in a certain range. Aggregation of information is always challenging especially when the input arguments are interrelated. To deal with such cases, the goal of this study is to develop the notion of the Maclaurin symmetric mean (MSM) operator as it aggregates information under uncertain environments and considers the relationship of the input arguments, which make it unique. In this paper, we studied the theory of MSM operators in the layout of PFSs and discussed their applications in the selection of the most suitable enterprise resource management (ERP) scheme for engineering purposes. We developed picture fuzzy MSM (PFMSM) operators and investigated their validity. We developed the multiattribute decision-making (MADM) algorithm based on the PFMSM operators to examine the performance of the ERP systems using picture fuzzy information. A numerical example to evaluate the performance of ERP systems is studied, and the effects of the associated parameters are discussed. The proposed aggregated results using PFMSM operators are found to be reliable as it takes into account the interrelationship of the input information, unlike traditional aggregation operators. A comparative study of the proposed PFMSM operators is also studied.

\section{Introduction}

Expert opinion under uncertain situation is a challenging task, and fuzzy set (FS) [1] developed by Zadeh is a useful tool to express the DM of elements. Later, the notion of FS was equipped by the DNM, and the frame of intuitionistic FS (IFS) was developed by Atanassov [2]. The frame of IFS was a flexible approach and has been utilized on a large account in the various real-life phenomena. The frame of IFS was strengthened by Yager $[3,4]$ as he introduces the notion of Pythagorean FS (PyFS) and q-rung orthopair FS (qROFS) by giving some flexibility in assigning the DM and the DNM. The frame of IFS, PyFS, and qROFS is based on the DM and the DNM only that accounts for describing two aspects of human opinion. It was suggested by Cuong and Kreinovich [5] who claim that the notion of IFS cannot describe the human perception properly as a human opinion have two more aspects known as DA and DR alongside the DM and the DNM and introduce the idea of PFS. Hence, expressing the human opinion using IFS, PyFS, and qROFS leads to loss of information in the absence of the DA and DR while the frame of PFS covered that possibly lost information shows the supremacy of PFS over the IFS, PyFS, and qROFS. From the application point of view, FS and its extension have some useful roles in parametric analysis and some differential equations as well $[6,7]$.

Aggregation of information is one of the challenging tasks in uncertain environments, and several aggregation operators (AOs) have been introduced in various fuzzy settings. Averaging and geometric AOs $[8,9]$ based on algebraic $\mathrm{t}$-norms ( $\mathrm{t}$-conorms) provide the aggregation of information and consider their weights into consideration. Einstein AOs $[10,11]$ are also used in the aggregation of information based on Einstein t-norm (t-conorm) and 
consider the weights of input information in the aggregation process. Dombi t-norms-based Dombi AOs [12-14] also handle uncertain information by taking into account their weights. By considering the prioritization among the input information, many prioritized AOs [15-17] have been studied for practical use in many fuzzy frameworks. Among the discussion of AOs, the theory of Hamacher AOs [18, 19] is also a prominent one, based on the Hamacher $t$-norm $(\mathrm{t}$ conorm), that takes the weight of the input arguments into account in aggregation steps. All the AOs discussed so far only aggregate the information and took only the weights into account. None of them consider the interrelationship of the input information. Due to this, some other types of aggregation operators are being developed including Heronian mean (HM) operators [20, 21], Bonferroni mean (BM) operators [22], hammy mean operators [23], power AOs [24], and MSM operators [25] which somehow relate the input information during the aggregation process. For some other significant work on MADM and aggregation theory, we refer to $[26,27]$.

MSM operators are among the widely studied topic in the theory of aggregation. Maclaurin [28] gave the idea of MSM operators for the first time and was popularized by DeTemple and Robertson [29]. The main feature of the MSM operator is that it takes into account the interrelationship of more than two input arguments at a time unlike BM operators and other traditional AOs, and hence the information fusion due to MSM operators is more robust and flexible. Intuitionistic fuzzy MSM (IFMSM) operators were proposed by Qin and Liu [30] while partitioned MSM operators for MADM purposes in the frame of IFSs have been studied by Liu et al. [31]. A study of Pythagorean fuzzy MSM (PyFMSM) operators and their application in the commercialization of the technology was investigated by Wei and Lu [32] while Yang and Pang [33] revisited PyFMSM operators by developing interactive PyFMSM operators for MADM purposes. Wei et al. [34] developed some q-rung orthopair fuzzy MSM (QROFMSM) operators for the evaluation of ERP systems using the MADM approach. Liu et al. [35] proposed power QROFMSM operators by merging power AO with QROFMSM operators for decision-making approaches. Wang et al. [36] extended the notion of QROFMSM operators to the frame of interval-valued qROFSs by expressing the DM and the DNM using a closed subinterval of $[0,1]$. The MSM operators in hesitant fuzzy settings were proposed by Qin et al. [37] while the MSM operators for linguistic variables in the intuitionistic fuzzy layout were discussed by Liu and Qin [38]. For some other useful work on the theory and applications of MSM operators, one can refer to [39-41].

The ability of PFS of describing uncertain information using DM, DNM, DA, and DR signifies its importance in dealing with the problems of MADM, pattern recognition, clustering, and medical diagnosis. Further, it has been noticed that the traditional aggregation operators only give us aggregation of information but do not correlate the input information and hence lost credibility to some extent. MSM operators overcome this disadvantage of the traditional aggregation operators by correlating the input information.
By keeping in mind, the diverse structure of PFSs where four aspects of uncertain information can be described that reduces the chances of information loss and the significance of MSM operators, our aim in this paper is to develop the notion of MSM operators for PFSs. The newly developed PFMSM operators can aggregate uncertain information by considering the relationship of more than two input arguments at a time. This type of AOs provides us robustness and flexibility and reduces information loss. The main contributions of this paper are summarized as follows:

(1) The notion of the MSM operator is introduced in the frame of PFSs to describe the four possible aspects of human opinion under uncertainty

(2) The superiority of the proposed MSM operators is shown using some remarks and using a comparative study of proposed and previous approaches

(3) The significance of the PFMSM operators is shown using a MADM problem numerically by discussing the performance of ERP systems.

The manuscript is designed such that Section 1 summarizes a history of different AOs and their drawbacks and the significance of the newly developed PFMSM operators. In Section 2, some basic definitions are recalled. In Section 3, we developed the theory of the PFMSM operator and picture fuzzy weighted MSM (PFWMSM) operator. In Section 4, we proposed a picture fuzzy dual MSM (PFDMSM) operator and a picture fuzzy weighted dual MSM (PFWDMSM) operator. In Section 5, it is proved that the proposed MSM operators are advanced than the MSM operators of IFSs. In Section 6, the MADM procedure is elaborated and a comprehensive numerical example is discussed where the selection of the best ERP scheme is carried out. In Section 7, we analyzed the comparative study of the existing and newly developed operators numerically. Section 8 consists of some conclusive remarks.

\section{Preliminaries}

In this part of the paper, some preliminary concepts are studied as a recall. We recall the notion of PFS and its supremacy over IFS. We also discuss the basic algebraic operations of PFSs that are used in our new study. The idea of ranking of picture fuzzy numbers (PFNs) is also recalled. It is to be noted that in this paper, by $\ddot{X}$, we mean a nonempty set and trios $\left(m^{\prime}, \mathrm{a}, d\right)$ denotes the DM, DA, and DNM of PFNs. Further, $\mathrm{J}=1,2,3, \ldots, n$ and $k=$ $1,2,3, \ldots, n$ shall be used as indexing terms.

Definition 1 (see [5]). A PFS is of the form $p^{\prime}=$ $\left\{\left(\ddot{X},\left(m^{\prime}(\ddot{X}), \underset{\mathrm{a}}{(\ddot{X})}, d(\ddot{X})\right)\right): \ddot{X} \in \ddot{X}\right\} \quad$ with $\quad 0 \leq m^{\prime q}(\ddot{X})+$ $\mathrm{a}^{q}(\ddot{X})+d^{q}(\ddot{X}) \leq 1, q \in \mathbb{Z}^{+}$. Also, $\quad r(\ddot{X})=\sqrt[q]{1-\left(m^{\prime q}(\ddot{X})\right.}+$ $\left.\mathrm{a}^{q}(\ddot{X})+d^{q}(\ddot{X})\right)$ is termed as the DR.

Definition 2 (see [9]). Let $p^{\prime}=\left(m^{\prime}, \underset{a}{\mathrm{a}}, d\right), p_{1}^{\prime}=\left(m_{1}^{\prime}, \mathrm{a}_{1}, d_{1}\right)$, and $p_{2}^{\prime}=\left(m_{2}^{\prime}, \mathrm{a}_{2}, d_{2}\right)$ be three PFNs and $y>0$. Then, 


$$
\begin{aligned}
p_{1}^{\prime} \oplus p_{2}^{\prime} & =\left(m_{1}^{\prime}+m_{2}^{\prime}-m_{1}^{\prime} m_{2}^{\prime}, \mathrm{a}_{1} \mathrm{a}_{2}, d_{1} d_{2}\right), \\
p_{1}^{\prime} \oplus p_{2}^{\prime} & =\left(m_{1}^{\prime} m_{2}^{\prime}, \mathrm{a}_{1}+\mathfrak{a}_{2}+\mathfrak{a}_{1} \cdot \mathrm{a}_{2}, d_{1}+d_{2}-d_{1} \cdot d_{2}\right), \\
y p^{\prime} & =\left(1-\left(1-m^{\prime}\right)^{y}, \mathrm{a}^{y}, d^{y}\right), \\
\left(p^{\prime}\right)^{y} & =\left(m^{\prime y}, 1-\left(1-a_{2}\right)^{y}, 1-(1-d)^{y}\right), \\
\left(p^{\prime c}\right) & =\left(d, a_{1}, m^{\prime}\right) .
\end{aligned}
$$

For the comparison of two PFNs $p_{\mathfrak{i}}^{\prime}=\left(m_{\mathfrak{i}}^{\prime}, a_{\mathfrak{i}}, d_{\mathfrak{i}}\right)$ and $p_{2}^{\prime}=\left(m_{2}^{\prime}, a_{2}, d_{2}\right)$, we have the following score function:

$$
S^{\prime}\left(p^{\prime}\right)=p_{\mathfrak{i}}^{\prime}=m_{\mathfrak{i}}^{\prime}-d_{\mathfrak{i}} \cdot r_{\mathfrak{i}}, S^{\prime}\left(p^{\prime}\right) \in[-1,1] .
$$

Definition 3 (see [28]). For a family of positive numbers $P_{p}^{\prime}$ the MSM operator is given by

$$
\operatorname{MSM}^{K}\left(P_{1}^{\prime}, P_{2}^{\prime}, \ldots, P_{n}^{\prime}\right)=\left(\sum_{1 \leq \mathfrak{i}_{1} \leq \cdots \leq \mathfrak{i}_{k} \leq n} \frac{\prod_{J=1}^{k} P_{\mathfrak{i}_{J}}^{\prime}}{C_{n}{ }^{\prime k}}\right)^{1 / k} .
$$

The term $C_{n}{ }^{\prime} k$ denotes a binominal coefficient throughout this paper. The above-defined MSM operator is likely to satisfy the following:

$$
\begin{aligned}
& \operatorname{MSM}^{K}(0,0, \ldots, 0)=0, \\
& \operatorname{MSM}^{K}\left(P^{\prime}, P^{\prime}, \ldots, P^{\prime}\right)=P^{\prime} \\
& \operatorname{MSM}^{K}\left(P_{1}^{\prime}, P_{2}^{\prime}, \ldots, P_{n}^{\prime}\right) \leq \operatorname{MSM}^{K}\left(Q_{1}, Q_{2}, \ldots, Q_{n}\right) \text { if } P_{\mathfrak{i}}^{\prime} \leq Q_{\mathfrak{i}} \forall \mathrm{i}, \\
& m^{\prime} \operatorname{in}\left\{P_{\mathfrak{i}}^{\prime}\right\} \leq \operatorname{MSM}^{K}\left(P_{1}^{\prime}, P_{2}^{\prime}, \ldots, P_{n}^{\prime}\right) \leq m^{\prime} a x\left\{P_{\mathfrak{i}}^{\prime}\right\} .
\end{aligned}
$$

Definition 4 (see [32]). For a family of positive numbers $P^{\prime}{ }_{J^{\prime}}$, the dual MSM (DMSM) operator is given by

$$
\operatorname{DMSM}^{K}\left(P_{1}^{\prime}, P_{2}^{\prime}, \ldots, P_{n}^{\prime}\right)=\frac{1}{k}\left(\prod_{\substack{1 \leq \mathfrak{i}_{1} \leq,,<\mathfrak{i}_{k} \leq n}}\left(\sum_{J=1}^{k} P_{\mathfrak{i} j}^{\prime}\right)^{1 / \zeta_{n}{ }^{k}}\right) .
$$

Now, we present some MSM operators that are discussed already and analyze their weaknesses. The notion of MSM operator has been discussed by several authors including Qin and Liu [30], Liu et al. [31], Wei and Lu [32], Yang and Pang [33], Wei et al. [34], Liu et al. [35], Wang et al. [36], Qin et al. [37], Liu and Qin [38], Wang et al. [39], Yu et al. [40], and Ju et al. [41]. We already discussed the significance of the MSM operators earlier. Our aim here is to point out the shortcomings of the previously defined MSM operators and to clear the objectives of proposing the new MSM operators in a picture fuzzy frame.

First, we present the MSM operators of IFSs [30] as follows:

$$
\begin{aligned}
& \operatorname{PFMSM}\left(P_{1}^{\prime}, P_{2}^{\prime}, P_{3}^{\prime}, \ldots, P_{n}^{\prime}\right)
\end{aligned}
$$

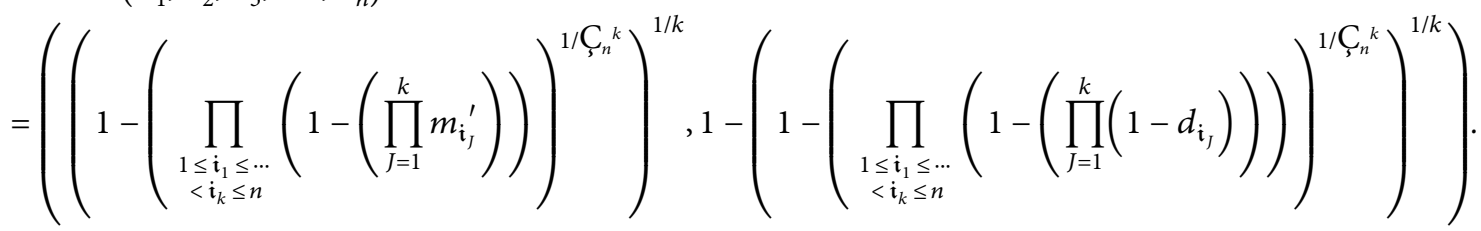

There are two issues with the MSM operators of IFSs; first, it has a strict condition in assigning the DM and DNM hence provide very little flexibility to decision-makers.
Second, it discusses only two aspects of human opinion using the DM and the DNM; hence, information loss occurs. follows:

$$
\begin{aligned}
& \operatorname{PyFMSM}\left(P_{1}^{\prime}, P_{2}^{\prime}, P_{3}^{\prime}, \ldots P_{n}^{\prime}\right)
\end{aligned}
$$

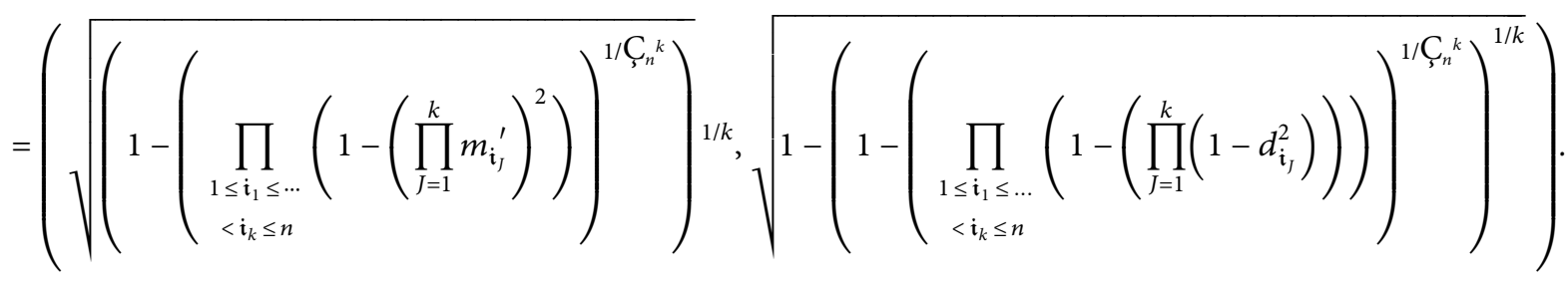


The MSM operators in the Pythagorean fuzzy frame only enlarge the range for assigning the DM, and the DNM is comparative to the MSM operators of IFSs but it also has the case of information loss due to the absence of the DA and
DR. To relax the restriction on the DM and DNM, Wei et al. [34] proposed the MSM operators in q-rung orthopair fuzzy settings given as follows:

$$
\begin{aligned}
& \operatorname{qROFMSM}\left(P_{1}^{\prime}, P_{2}^{\prime}, P_{3}^{\prime}, \ldots, P_{n}^{\prime}\right) \\
& =\left(\sqrt[q]{\left(1-\left(\prod_{\substack{1 \leq \mathfrak{i}_{1} \leq \ldots \\
<\mathfrak{i}_{k} \leq n}}\left(1-\left(\prod_{J=1}^{k} m_{\mathfrak{i}_{J}}^{\prime}\right)^{q}\right)\right)^{1 / \zeta_{n}{ }^{k}}\right)} 1 / k, \sqrt[q]{1-\left(1-\left(\prod_{\substack{1 \leq \mathfrak{i}_{1} \leq \ldots . \\
<\mathfrak{i}_{k} \leq n}}\left(1-\left(\prod_{J=1}^{k}\left(1-d_{\mathfrak{i}_{J}}^{q}\right)\right)\right)^{1 / \zeta_{n}{ }^{k}}\right)^{1 / k}\right) .}\right.
\end{aligned}
$$

The MSM operators of qROFSs also have the problem of information loss due to the absence of DA and DR. Due to this fact, this paper aims to introduce the notion of MSM operators in a picture fuzzy setting. The main objective is to reduce information loss by incorporating the four aspects of uncertain information.

\section{Picture Fuzzy MSM Operators}

The goal of this section is to introduce the MSM operators using a DM, DNM, DA, and DR in the layout of PFNs. We develop PFMSM and PFWMSM operators using the notion of MSM and WMSM in the layout of PFSs. In our onward study, we shall mean by $\omega_{j}=\left(\omega_{1}, \omega_{2}, \ldots \omega_{n}\right)^{\mathrm{T}}$ the weight vector of $p_{j}^{\prime}$ where $\omega_{j}>0$, and $\sum_{j=1}^{n} \omega_{j}=1$.
Definition 5. Let $P_{j}^{\prime}=\left(m_{j}^{\prime}, a_{j}, d_{j}\right)$ denote a collection of PFNs. Then, the PFMSM operator is given by

$$
\operatorname{PFMSM}^{k}\left(P_{1}^{\prime}, P_{2}^{\prime}, P_{3}^{\prime}, \ldots, P_{n}^{\prime}\right)=\left(\frac{\underset{1 \leq \mathfrak{i}_{1} \leq \cdots \mathfrak{i}_{k} \leq n}{\oplus}\left(\otimes_{j=1}^{k} P_{\mathfrak{i}_{j}^{\prime}}^{\prime}\right)}{\dot{C}_{n}^{k}}\right)^{1 / k} .
$$

Theorem 1. Let $P_{j}^{\prime}=\left(m_{j}^{\prime}, a_{j}, d_{j}\right)$ denote a collection of PFNs. Then, using PFMSM operators, we have

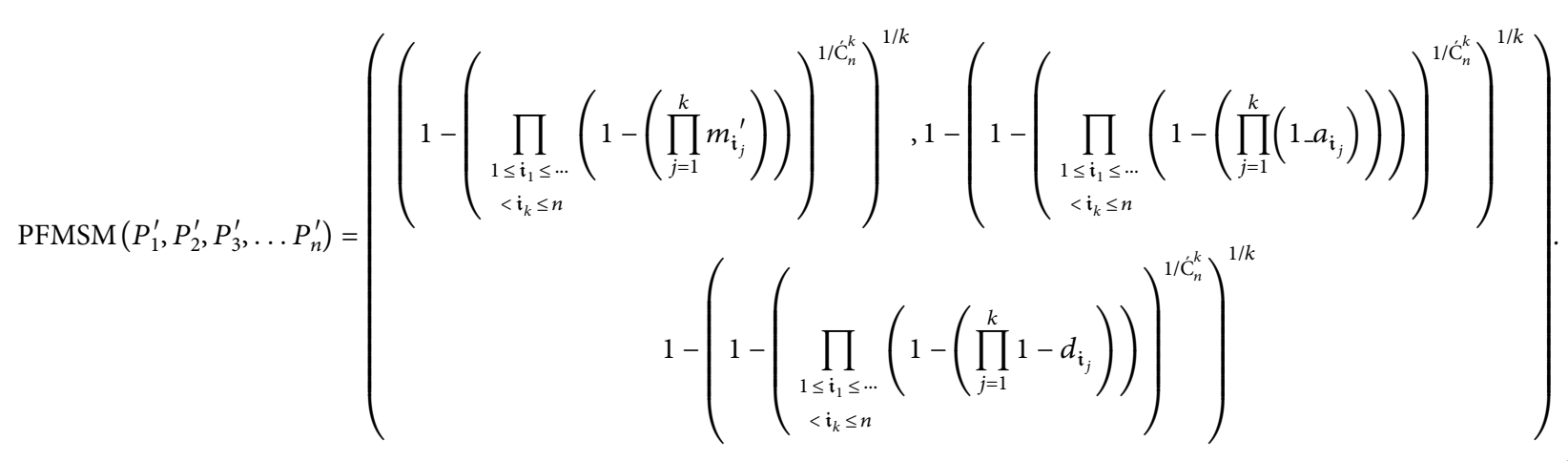

Proof. By using Definition 5, we have 


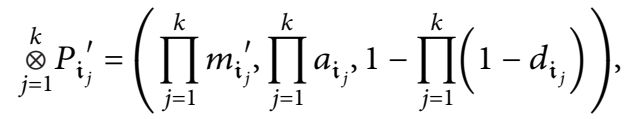

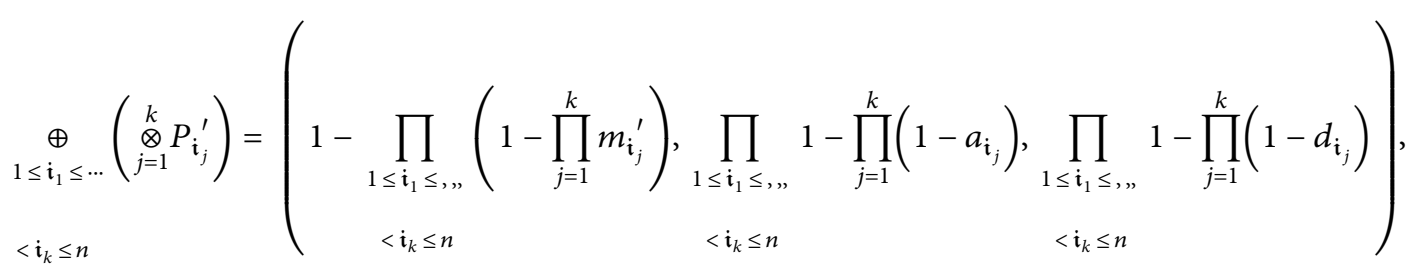

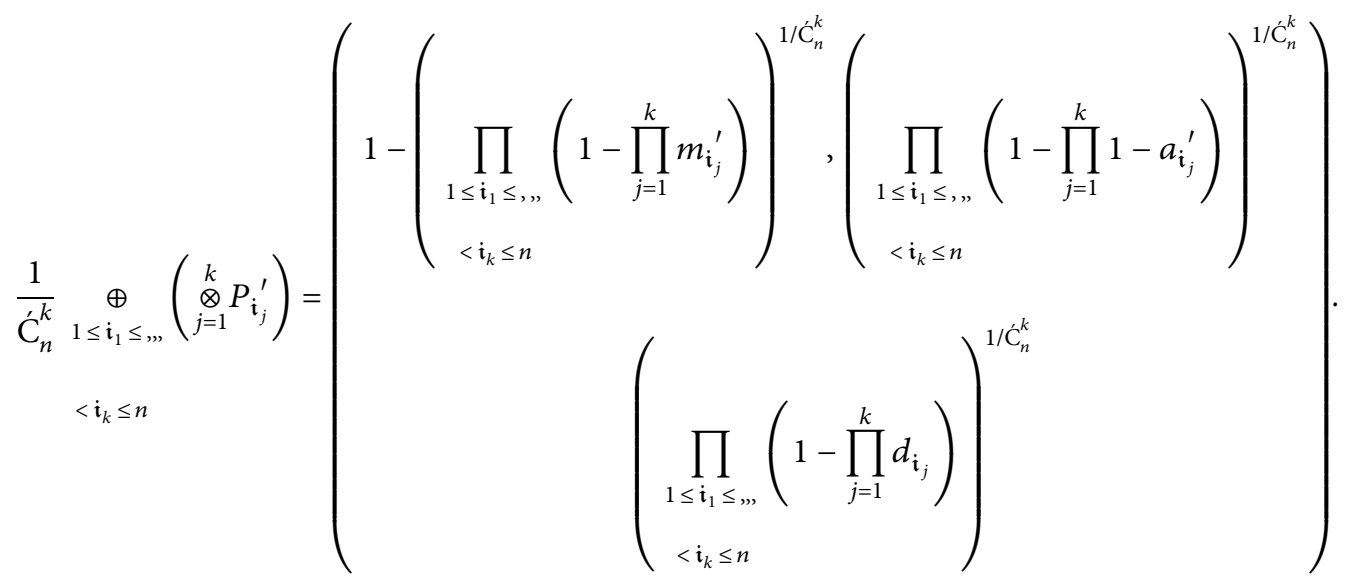

Therefore,

$$
\begin{aligned}
& \operatorname{PFMSM}\left(P_{1}^{\prime}, P_{2}^{\prime}, \ldots, P_{n}^{\prime}\right)= \\
& \left(\begin{array}{c}
\left.\left(\prod_{\substack{1 \leq \mathfrak{i}_{1} \leq \ldots \\
<\mathfrak{i}_{k} \leq n}}\left(1-\left(\prod_{j=1}^{k} m_{\mathfrak{i}_{j}}^{\prime}\right)\right)\right)^{1 / \dot{C}_{n}^{k}}\right)^{1 / k}, 1-\left(1-\left(\prod_{\substack{1 \leq \mathfrak{i}_{1} \leq \ldots \\
<\mathfrak{i}_{k} \leq n}}\left(1-\left(\prod_{j=1}^{k}\left(1-a_{\mathfrak{i}_{j}}\right)\right)\right)\right.\right. \\
\left.\left.1-\left(1-\left(\prod_{\substack{1 \leq \mathfrak{i}_{1} \leq \ldots \\
<\mathfrak{i}_{k} \leq n}}\left(1-\left(\prod_{j=1}^{k}\left(1-d_{\mathfrak{i}_{j}}\right)\right)\right)\right)^{1 / \dot{C}_{n}^{k}}\right)^{1 / k}\right)^{1 / k}\right)
\end{array}\right.
\end{aligned}
$$

The above-defined PFMSM operator satisfies the basic characteristics of aggregation given as follows.

Property 1. Let $P_{J}^{\prime}=\left(m_{J}^{\prime}, \mathrm{a}_{J}, d_{J}\right)$ denote a collection of PFNs. If $P_{j}^{\prime}=P^{\prime}$, then

$$
\operatorname{PFMSM}\left(P_{1}^{\prime}, P_{2}^{\prime}, P_{3}^{\prime}, \ldots, P_{n}^{\prime}\right)=P^{\prime} .
$$

Property 2. Let $P_{J}^{\prime}$ and $P_{3}^{\prime}$ denote the collections of PFNs if $m_{J}^{\prime} \geq m_{3}^{3}, \mathrm{a}_{J} \leq \mathrm{a}_{3}$, and $d_{J} \leq d_{3}$. Then,

$$
\operatorname{PFMSM}\left(P_{1}^{\prime}, P_{2}^{\prime}, P_{3}^{\prime}, \ldots P_{n}^{\prime}\right) \geq \operatorname{PFMSM}\left(P_{1}^{\prime}, P_{2}^{\prime}, \ldots, P_{3}^{\prime}\right)
$$

Property 3. Let $P_{J}^{\prime}=\left(m_{J}^{\prime}, \underset{t}{\mathrm{a}_{J}}, d_{J}\right)$ denote a collection of PFNs such that

$$
\begin{aligned}
& P^{\prime^{-}}=\min P_{J}^{\prime}=\left(\min m_{J}^{\prime}, \max \underset{J}{a}, \max d_{J}\right), \\
& P^{\prime+}=\max P_{J}^{\prime}=\left(\max m_{J}^{\prime}, \min a_{J}, \min d_{J}\right) \text {. }
\end{aligned}
$$

Then, 


$$
{P^{\prime}}^{-} \leq \operatorname{PFMSM}\left(P_{1}^{\prime}, P_{2}^{\prime}, P_{3}^{\prime}, \ldots P_{n}^{\prime}\right) \leq{P^{\prime+}}^{+}
$$

Weighted aggregation operators have always their significance and incorporate the weight vector of an aggregation phenomenon. In the following, we define weighted MSM operators for PFNs.

$$
\operatorname{PFWMSM}\left(P_{1}^{\prime}, P_{2}^{\prime}, \ldots, P_{n}^{\prime}\right)=\left(\frac{\underset{1 \leq \mathfrak{i}_{1} \leq \cdots i_{k} \leq n}{\oplus}\left(\otimes_{J=1}^{k} P_{\mathfrak{i}_{J}^{\prime}}^{\prime}\right)^{w_{\mathfrak{i}_{J}}}}{\dot{\mathrm{C}}_{n}^{k}}\right)^{1 / k} .
$$

Definition 6. Let $P_{J}^{\prime}=\left(m_{J}^{\prime}, \mathrm{a}_{J}, d_{J}\right)$ denote a collection of PFNs. Then, the PFWMSM operator is given by
Theorem 2. Let $P_{J}^{\prime}=\left(m_{J}^{\prime}, a_{J}, d_{J}\right)$ denote a collection of PFNs. Then, using the PFWMSM operator, we have

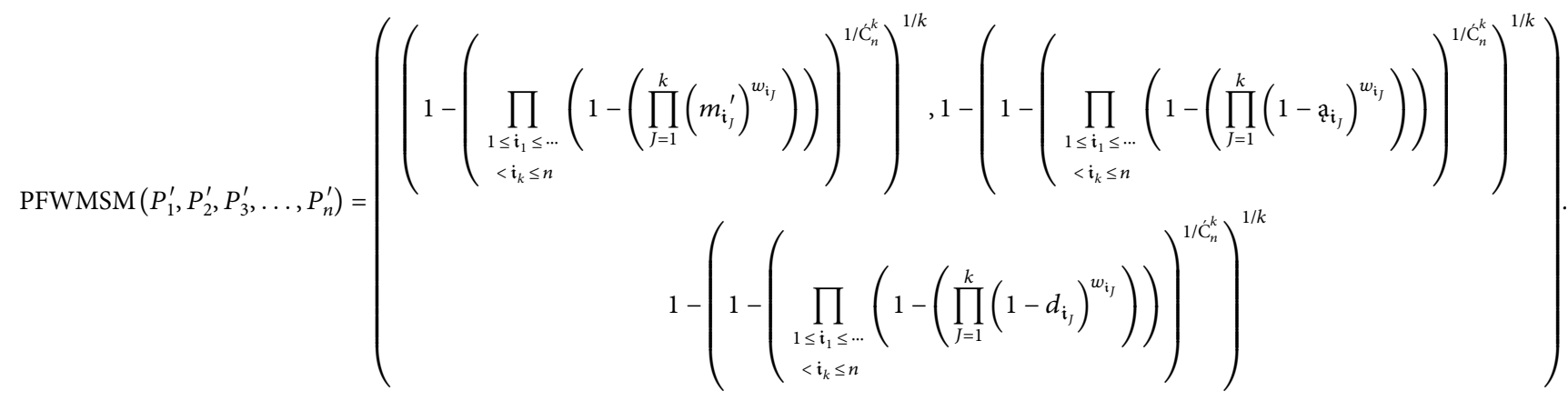

Proof. Similar to Theorem 1.

\section{Picture Fuzzy Dual MSM Operators}

This section aims to introduce the notion of PFSMSM operators using the DM, DNM, DA, and DR. We propose PFDMSM operator and PFWDMSM operator.

Definition 7. Let $P_{J}^{\prime}=\left(m_{J}^{\prime}, \mathrm{a}_{J}, d_{J}\right)$ denote a collection of PFNs. Then, the PFDMSM operator is given by

$$
\operatorname{PFDMSM}^{K}\left(P_{1}^{\prime}, P_{2}^{\prime}, \ldots, P_{n}^{\prime}\right)=\frac{1}{k}\left(\underset{\substack{1 \leq \mathfrak{i}_{1} \leq \ldots \\<i_{k} \leq n}}{\oplus}\left(\underset{J=1}{\stackrel{k}{\otimes}} P_{\mathfrak{i}_{J}^{\prime}}^{\prime}\right)^{1 / \dot{C}_{n}^{k}}\right) .
$$

Theorem 3. Let $P_{J}^{\prime}=\left(m_{J}^{\prime}, a_{J}, d_{J}\right)$ denote a collection of PFNs. Then, by using PFDMSM, we have

$$
\operatorname{PFDMSM}\left(P_{1}^{\prime}, P_{2}^{\prime}, \ldots, P_{n}^{\prime}\right)=\left(\begin{array}{l}
1-\left(1-\prod_{\substack{1 \leq \mathfrak{i}_{1} \leq, \ldots \\
<\mathfrak{i}_{k} \leq n}}\left(1-\prod_{J=1}^{k}\left(1-m_{J}^{\prime}\right)\right)^{1 / \dot{C}_{n}^{k}}\right)^{1 / k}\left(1-\left(\prod_{\substack{1 \leq \mathfrak{i}_{1} \leq, \ldots \\
<\mathfrak{i}_{k} \leq n}}\left(1-\left(\prod_{J=1}^{k} \mathfrak{a}_{\mathfrak{i}_{J}}\right)\right)\right)^{1 / \mathbf{C}_{n}^{k}}\right)^{1 / k}, \\
\left.\left(\prod_{\substack{1 \leq \mathfrak{i}_{1} \leq, \ldots \\
<\mathfrak{i}_{k} \leq n}}\left(1-\left(\prod_{J=1}^{k} d_{\mathfrak{i}_{J}}\right)\right)\right)^{1 / \mathbf{C}_{n}^{k}}\right)^{1 / k}
\end{array}\right) .
$$

Proof. Using Definition 7, we have 


$$
\begin{aligned}
& \underset{J=1}{\otimes} P_{\mathfrak{i}_{J}}^{\prime}=\left(1-\prod_{J=1}^{k}\left(1-m_{\mathfrak{i}_{J}}^{\prime}\right), \prod_{J=1}^{k} \mathfrak{a}_{\mathfrak{i}_{J}}, \prod_{J=1}^{k} d_{\mathfrak{i}_{J}}\right) \\
& \left(\underset{J=1}{\otimes} P_{\mathfrak{i}_{J}}^{\prime}\right)^{1 / \dot{C}_{n}^{\prime}}=\left(\left(1-\prod_{J=1}^{k}\left(1-m_{\mathfrak{i}_{J}}^{\prime}\right)\right)^{1 / \dot{\mathrm{C}}_{n}^{k}}, 1-\left(1-\left(\prod_{J=1}^{k} \mathfrak{a}_{\mathfrak{i}_{J}}\right)\right)^{1 / \dot{\mathrm{C}}_{n}^{k}}, 1-\left(1-\left(\prod_{J=1}^{k} d_{\mathfrak{i}_{J}}\right)\right)^{1 / \dot{\mathrm{C}}_{n}^{k}}\right),
\end{aligned}
$$

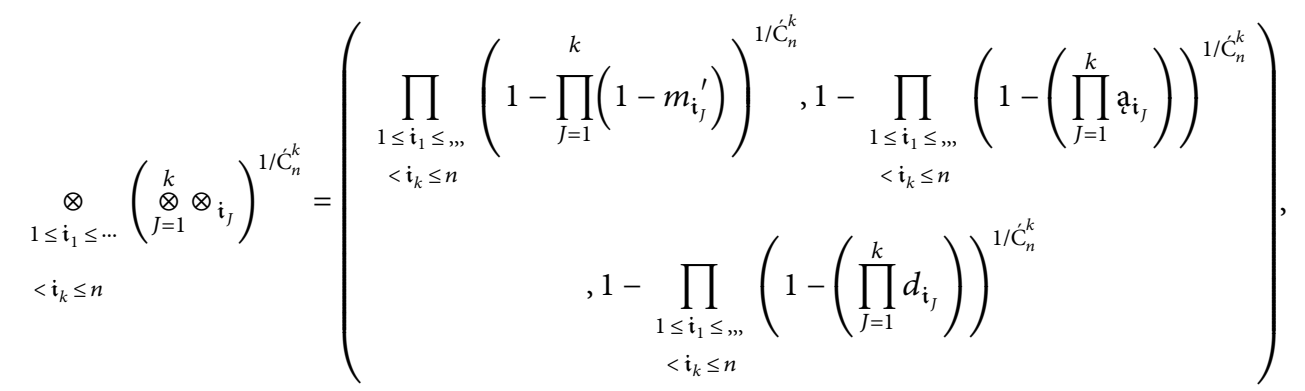

$$
\begin{aligned}
& \left.\operatorname{PFDMSM}\left(P_{1}^{\prime}, P_{2}^{\prime}, \ldots, P_{n}^{\prime}\right)=\left(1-\left(1-\prod_{\substack{1 \leq \mathfrak{i}_{1} \leq,,<\mathfrak{i}_{\mathrm{k}} \leq n}}\left(1-\prod_{J=1}^{\mathrm{k}}\left(1-m_{J}^{\prime}\right)\right)^{1 / \dot{\mathrm{C}}_{n}^{\mathrm{k}}}\right)^{1 / \mathrm{k}},\left(1-\left(\prod_{\substack{1 \leq \mathfrak{i}_{1} \leq,, \ldots \\
<\mathfrak{i}_{\mathrm{k}} \leq n}}\left(1-\left(\prod_{J=1}^{\mathrm{k}} \mathrm{a}_{\mathfrak{i}_{J}}\right)\right)^{1 / \mathrm{k}}\right)^{1 / \dot{c}_{n}^{k}}\right)^{1 / \dot{\mathrm{c}}_{n}^{k}}\right)^{1 / \mathrm{k}}\right) .
\end{aligned}
$$

The above-defined PFDMSM operator is likely to satisfy the following characteristics of aggregation.

Property 4. Let $P_{J}^{\prime}=\left(m_{J}^{\prime}, \underset{t}{\mathrm{a}}, d_{J}\right)$ denote a collection of PFNs. If $P_{J}^{\prime}=P^{\prime}$, then

$$
\operatorname{PFDMSM}\left(P_{1}^{\prime}, P_{2}^{\prime}, P_{3}^{\prime}, \ldots, P_{n}^{\prime}\right)=P^{\prime} .
$$

Property 5. Let $P_{J}^{\prime}$ and $P_{3}^{\prime}$ denote the collections of PFNs if $m_{J}^{\prime} \geq m_{3}^{\prime}, \mathrm{a}_{J} \leq \mathrm{a}_{J}$, and $d_{J} \leq d_{3}$. Then,

$$
\operatorname{PFDMSM}\left(P_{1}^{\prime}, P_{2}^{\prime}, \ldots, P_{J}^{\prime}\right) \geq \operatorname{PFDMSM}\left(P_{1}^{\prime}, P_{2}^{\prime}, \ldots, P_{3}^{\prime}\right) \text {. }
$$

Property 6. Let $P_{J}^{\prime}=\left(m_{J}^{\prime}, \mathrm{a}_{J}, d_{J}\right)$ denote a collection of PFNs such that

$$
\begin{aligned}
& P^{\prime^{-}}=\min P_{J}^{\prime}=\left(\min m_{J}^{\prime}, \max {\underset{\tau}{J}}_{J}, \max d_{J}\right), \\
& {P^{\prime+}}^{+}=\max P_{J}^{\prime}=\left(\max m_{J}^{\prime}, \min {\underset{\iota}{J}}_{J}, \min d_{J}\right) .
\end{aligned}
$$

Then,

$$
P^{\prime^{-}} \leq \operatorname{PFDMSM}\left(P_{1}^{\prime}, P_{2}^{\prime}, P_{3}^{\prime}, \ldots, P_{n}^{\prime}\right) \leq{P^{\prime}}^{+}
$$

Definition 8. Let $P_{J}^{\prime}=\left(m_{J}^{\prime}, \mathrm{a}_{J}, d_{J}\right)$ denote a collection of PFNs. Then, the PFWDMSM operator is given by

$$
\operatorname{PFWDMSM}\left(P_{1}^{\prime}, P_{2}^{\prime}, \ldots P_{n}^{\prime}\right)=\frac{1}{k}\left(\underset{\substack{1 \leq \mathfrak{i}_{1} \leq \ldots \\<i_{k} \leq n}}{\oplus}\left(\underset{J=1}{\otimes}\left(\omega_{\mathfrak{i}_{J}} \otimes P_{\mathfrak{i}_{j}}^{\prime}\right)\right)^{1 / \dot{C}_{n}^{k}}\right)
$$

Theorem 4. Let $P_{J}^{\prime}=\left(m_{J}^{\prime}, a_{J}, d_{J}\right)$ denote a collection of PFNs. Then, using the PFWDMSM operator, we have 


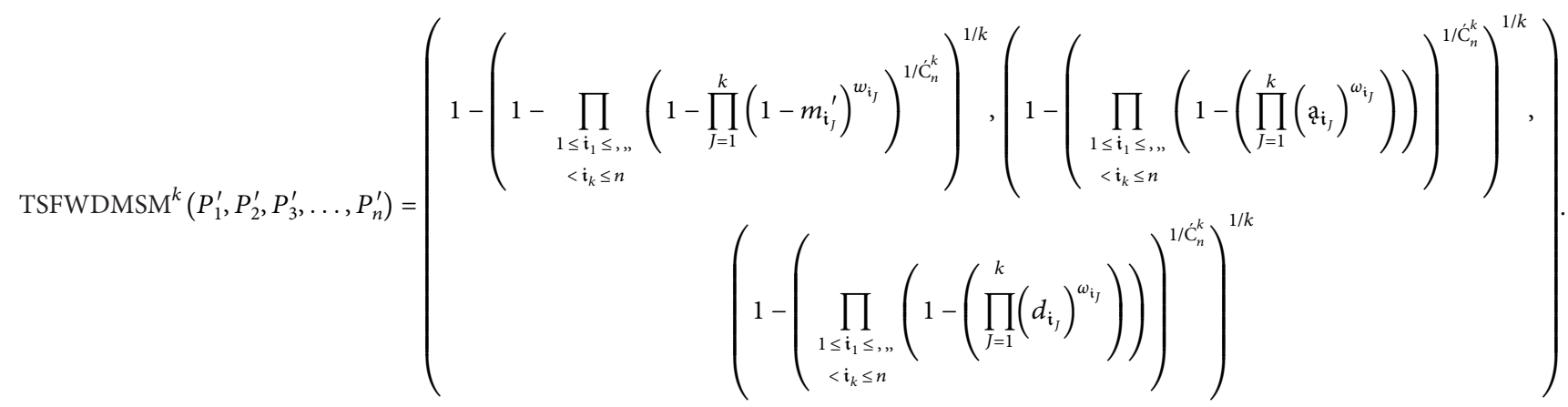

Proof. Similar as Theorem 3.

\section{Consequences of the PFMSM Operator}

This section aims to show the generalization of the PFMSM and PFDMSM operators over the MSM operators of IFSs.

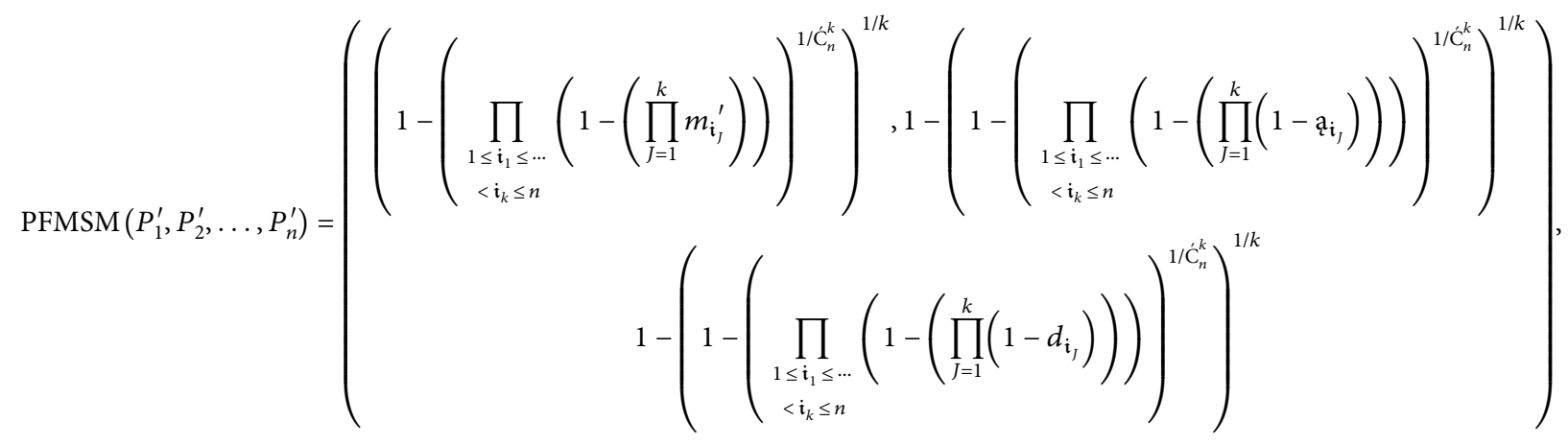

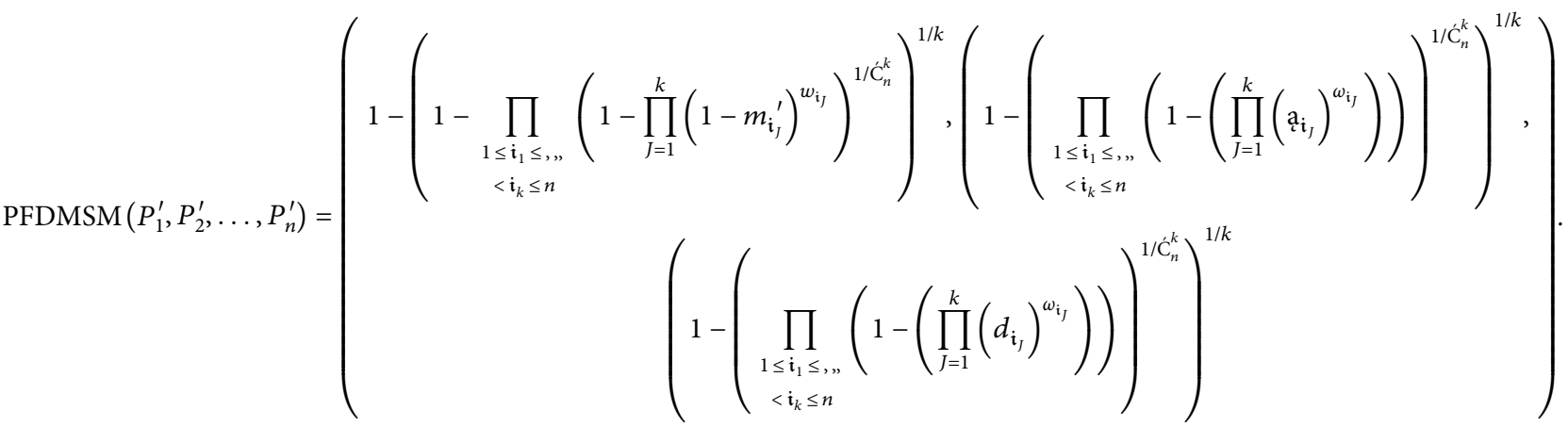

For $\mathrm{a}_{\mathfrak{i}_{\mathrm{I}}}=0$, the PFMSM and PFDMSM operators are reduced into the MSM operators of IFSs proposed by [30] and given as follows: 


$$
\begin{aligned}
& \operatorname{IFMSM}\left(P_{1}^{\prime}, P_{2}^{\prime}, P_{3}^{\prime}, \ldots P_{n}^{\prime}\right)=\left(\begin{array}{c}
\left.1-\left(\prod_{\substack{1 \leq \mathfrak{i}_{1} \leq \ldots \\
<\mathfrak{i}_{k} \leq n}}\left(1-\left(\prod_{J=1}^{k} m_{\mathfrak{i}_{j}}^{\prime}\right)^{1}\right)\right)^{1 / \dot{\mathrm{C}}_{n}^{k}}\right)^{1 / k} \\
\left.1-\left(1-\left(\prod_{\substack{1 \leq \mathfrak{i}_{1} \leq \ldots . \\
<\mathfrak{i}_{k} \leq n}}\left(1-\left(\prod_{J=1}^{k}\left(1-\left(d_{\mathfrak{i}_{J}}\right)^{1}\right)\right)\right)\right)^{1 / \dot{C}_{n}^{k}}\right)^{1 / k}\right)^{1 / k}
\end{array}\right) \\
& \operatorname{IFDMSM}\left(P_{1}^{\prime}, P_{2}^{\prime}, \ldots, P_{n}^{\prime}\right)=\left(1-\left(1-\prod_{\substack{1 \leq \mathfrak{i}_{1} \leq,, \ldots \\
<\mathfrak{i}_{k} \leq n}}\left(1-\prod_{J=1}^{k}\left(1-m_{J}^{\prime}\right)\right)^{1 / \dot{C}_{n}^{k}}\right)^{1 / k},\left(1-\left(\prod_{\substack{1 \leq \mathfrak{i}_{1} \leq,, \ldots \\
<\mathfrak{i}_{k} \leq n}}\left(1-\left(\prod_{J=1}^{k} d_{\mathfrak{i}_{J}}\right)\right)\right)^{1 / \dot{C}_{n}^{k}}\right)^{1 / k}\right) .
\end{aligned}
$$

\section{Picture Fuzzy MADM Procedure}

The goal of this paper is to study the procedure for MADM using picture fuzzy information based on MSM operators proposed in the earlier sections.

MADM is a procedure for the selection of the finest option, under uncertain environments, among a list of finite alternatives based on some attributes. The MADM procedure that we aim to adapt is based on the PFMSM operator and PFDMSM operators. Assume the set of alternatives + among which the best is to be chosen and the attribute set under observation be $G=\left\{G_{1}, G_{2}, \ldots, G_{m^{\prime}}\right\}$. The uncertain information is based on PFNs where the four facets of an expert's opinion are considered to evaluate all the alternatives. In the proposed approach, the experts are asked to evaluate the alternatives using PFNs in the form of a decision matrix and then the PFMSM and PFDMSM operators are utilized to aggregate the initial evaluation of the experts for the selection of the finest alternatives. The attributes used in the approach have their weights based on the expert's preferences. The detailed steps of the algorithm are given as follows:

Step 1. Initially, the experts evaluate the possible alternatives under the decided set of attributes using PFNs where they gave their opinion using a DM, DNM, DA, and DR under the restraints of PFSs.

Step 2. To deal with risk/cost factors, the risk is minimized by using the below-given equation where each risk/cost type of attribute is converted into a benefit type of attribute. The phenomenon is known as normalization.

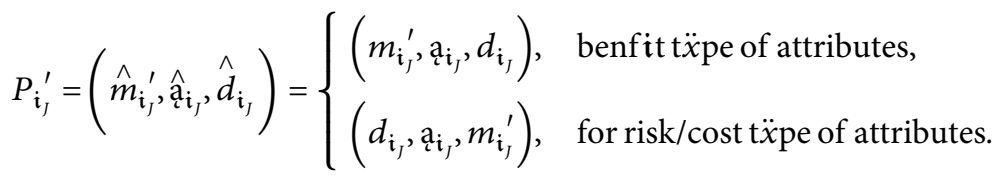

Step 3. Once done with normalizations, we utilize the following two MSM operators to aggregate the initial information normalized in Step 2.

Step 4. After the aggregation of picture fuzzy information, we use the score value of the PFNs (using Definition 2) to arrange the alternatives in ascending/ descending order based on the collected information.

Step 5. The last step involves the ranking of the given alternatives based on the score values obtained in the preceding step.

Technology commercialization is a challenging problem that has been discussed widely by various authors. In the current paper, we consider the ERP system problem discussed by [32]. ERP systems are of great capability in many engineering manufacturing companies. It eases human efforts by handling many tasks using its dynamic design.

The following numerical example is to demonstrates the MADM steps in detail.

Example 1. Consider a set of ERP schemes $\left\{\overline{\ddot{A}}_{1}, \overline{\ddot{A}}_{2}, \overline{\ddot{A}}_{3}, \overline{\ddot{A}}_{4}, \overline{\ddot{A}}_{5}\right\}$ that needs evaluation by experts. These ERP schemes are evaluated under a finite set of attributes denoted by $\left\{G_{1}, G_{2}, \ldots, G_{m^{\prime}}\right\}$. The target is to choose the optimum ERP schemes that suit best for the company. The attribute set is defined as follows: $G_{1}$ represents technical advancement; $G_{2}$ represents reducing human resources, $G_{3}$ represents economic advantages, and $G_{4}$ represents development of the company. Each attribute $G_{1}, G_{2}, \ldots, G_{m^{\prime}}$ is 
TABle 1: Evaluation remarks about ERP Schemes based on PFNs.

\begin{tabular}{|c|c|c|c|c|c|c|c|c|c|c|c|c|c|c|c|}
\hline & \multicolumn{3}{|c|}{$\ddot{A}_{1}$} & \multicolumn{3}{|c|}{$\ddot{A}_{2}$} & \multicolumn{3}{|c|}{$\ddot{A}_{3}$} & \multicolumn{3}{|c|}{$\ddot{A}_{4}$} & \multicolumn{3}{|c|}{$\ddot{A}_{5}$} \\
\hline & $\mathrm{DM}$ & DA & DNM & DM & DA & DNM & $\mathrm{DM}$ & DA & DNM & DM & DA & DNM & DM & DA & DNM \\
\hline $\mathrm{G}_{1}$ & 0.3 & 0.2 & 0.5 & 0.6 & 0.1 & 0.2 & 0.3 & 0.3 & 0.3 & 0.2 & 0.7 & 0.1 & 0.4 & 0.4 & 0.1 \\
\hline $\mathrm{G}_{2}$ & 0.4 & 0.3 & 0.1 & 0.8 & 0.1 & 0.1 & 0.2 & 0.5 & 0.3 & 0.6 & 0.3 & 0.1 & 0.3 & 0.4 & 0.3 \\
\hline $\mathrm{G}_{3}$ & 0.7 & 0.1 & 0.2 & 0.4 & 0.2 & 0.4 & 0.3 & 0.1 & 0.2 & 0.3 & 0.4 & 0.3 & 0.5 & 0.1 & 0.3 \\
\hline $\mathrm{G}_{4}$ & 0.2 & 0.4 & 0.3 & 0.2 & 0.2 & 0.5 & 0.4 & 0.3 & 0.3 & 0.7 & 0.1 & 0.1 & 0.5 & 0.3 & 0.2 \\
\hline
\end{tabular}

TABle 2: Aggregated results of Table 1 using picture fuzzy MSM operators.

\begin{tabular}{|c|c|c|c|c|c|c|c|c|c|c|c|c|c|c|c|}
\hline & \multicolumn{3}{|c|}{$\bar{A}_{1}$} & \multicolumn{3}{|c|}{$\ddot{A}_{2}$} & \multicolumn{3}{|c|}{$\ddot{\ddot{A}}_{3}$} & \multicolumn{3}{|c|}{$\bar{A}_{4}$} & \multicolumn{3}{|c|}{$\ddot{\ddot{A}}_{5}$} \\
\hline & $\mathrm{DM}$ & DA & DNM & $\mathrm{DM}$ & DA & DNM & $\mathrm{DM}$ & DA & DNM & $\mathrm{DM}$ & DA & DNM & $\mathrm{DM}$ & DA & DNM \\
\hline $\mathrm{G}_{1}$ & 0.36 & 0.32 & 0.29 & 0.44 & 0.15 & 0.32 & 0.29 & 0.31 & 0.28 & 0.40 & 0.42 & 0.15 & 0.42 & 0.31 & 0.23 \\
\hline $\mathrm{G}_{2}$ & 0.10 & 0.10 & 0.08 & 0.15 & 0.04 & 0.08 & 0.08 & 0.10 & 0.08 & 0.12 & 0.13 & 0.04 & 0.12 & 0.10 & 0.06 \\
\hline $\mathrm{G}_{3}$ & 0.44 & 0.32 & 0.23 & 0.56 & 0.15 & 0.25 & 0.30 & 0.31 & 0.27 & 0.49 & 0.42 & 0.13 & 0.43 & 0.31 & 0.21 \\
\hline $\mathrm{G}_{4}$ & 0.12 & 0.07 & 0.06 & 0.20 & 0.03 & 0.06 & 0.08 & 0.08 & 0.08 & 0.16 & 0.13 & 0.59 & 0.13 & 0.08 & 0.05 \\
\hline
\end{tabular}

Table 3: The score of the aggregated PFNs, obtained in Table 2.

\begin{tabular}{|c|c|c|c|c|c|}
\hline & $\operatorname{Score}\left(\ddot{\ddot{A}}_{1}\right)$ & Score $\left(\ddot{A}_{2}\right)$ & $\operatorname{Score}\left(\ddot{A}_{3}\right)$ & $\operatorname{Score}\left(\ddot{A}_{4}\right)$ & Score $\left(\ddot{A}_{5}\right)$ \\
\hline PFMSM & 0.35121 & 0.414797 & 0.258776 & 0.394238 & 0.405949 \\
\hline PFWMSM & 0.03978 & 0.088813 & 0.020347 & 0.09474 & 0.075623 \\
\hline PFDMSM & 0.433926 & 0.54734 & 0.273624 & 0.496403 & 0.419766 \\
\hline PFWDMSM & 0.073764 & 0.158918 & 0.024447 & 0.134875 & 0.085704 \\
\hline
\end{tabular}

associated by a weight given the weight vector $\omega_{J}=(0.29,0.31,0.17,0.23)^{T}$. The selection process of the most suitable ERP scheme is elaborated as follows.

Step 1. The decision panel of the company, after analyzing initially securitized 5 ERP schemes, evaluated their performances and gave their opinion using PFNs. The evaluation information is given in Table 1 .

Step 2. This step involves normalization but, in this case, it does not occur as all the attributes are of benefit type.

Step 3. This step involves the aggregation of uncertain information based on PFNs using PFMSM, PFWMSM, PFDMSM, and PFWDMSM operators. We apply the four newly developed MSM operators, and the results are portrayed in Table 2.

Step 4. This step involves the definition of the ranking function. We computed the scores of the data obtained in Table 2, and the results are given in Table 3.

Step 5. This step involves the ranking of the ERP schemes in order to get the optimum result. All the ERP schemes are ranked in Table 4.

For better understanding, the ranking results of Table 4 are shown in Figure 1.

After analyzing Table 4 and Figure 1, it is evident that PFMSM, PFDMSM, and PFWDMSM operators give us the ERP scheme $\ddot{A}_{2}$ as the most effective one while the PFWMSM operators give us $\ddot{A}_{4}$ as best one. The selection of any MSM operators is based on the preference of the experts.
TABLE 4: Ranking of ERP schemes.

\begin{tabular}{ll}
\hline Methods & Ranking values \\
\hline PFMSM & $\ddot{\ddot{A}}_{2} \geq \ddot{\ddot{A}}_{5} \geq \ddot{\ddot{A}}_{4} \geq \ddot{\ddot{A}}_{1} \geq \ddot{\ddot{A}}_{3}$ \\
TSFWMSM & $\ddot{\ddot{A}}_{4} \geq \ddot{\ddot{A}}_{2} \geq \ddot{\ddot{A}}_{4} \geq \ddot{\ddot{A}}_{1} \geq \ddot{\ddot{A}}_{3}$ \\
TSFDMSM & $\ddot{\ddot{A}}_{2} \geq \ddot{\ddot{A}}_{4} \geq \ddot{\ddot{A}}_{1} \geq \ddot{\ddot{A}}_{3}$ \\
TSFWDMSM & $\ddot{A}_{2} \geq \ddot{A}_{3} \geq \ddot{A}_{3}$ \\
\hline
\end{tabular}

It is to be noted that all of them can give us different results, and getting the same results is not a necessary option. Further, we took $\mathrm{k}=4$ in our discussed problem to take into account the relationship of all four ERP schemes. Varying $\mathrm{k}$ may also vary the results.

\section{Comparative Analysis}

The goal of this section is to set up a comparative study of the newly developed MSM operators with other existing AOs of PFNs.

PFS is an advanced frame where uncertain information can be expressed with less information loss in a certain range. A great number of AOs are being developed in the few years. Here, we aim to investigate the comparison of the MSM operators with other AOs of PFNs numerically to see the validity of the proposed MSM operators. We apply the Hamacher AOs of PFN proposed by Wei [19], picture fuzzy arithmetic and geometric AOs proposed by Garg [9], picture fuzzy Dombi AOs proposed by Jana et al. [12] to the problem discussed in Example 1, and portray the results in Table 5. 


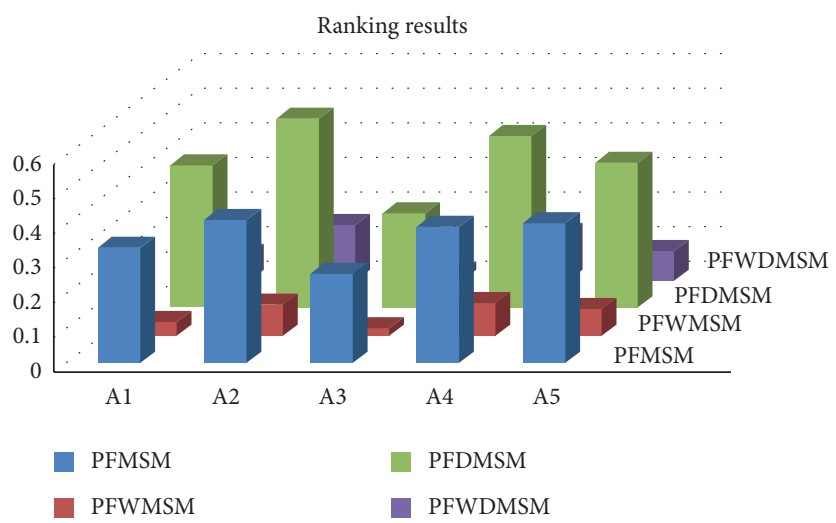

Figure 1: Ranking results of Table 4.

TABLE 5: Comparative analysis of the proposed operators with some existing operators.

\begin{tabular}{|c|c|c|c|c|c|c|}
\hline Operators & $\dot{S}\left(\overline{\ddot{A}}_{1}\right)$ & $\dot{S}\left(\overline{\mathscr{A}}_{2}\right)$ & $\dot{S}\left(\bar{A}_{3}\right)$ & $\dot{S}\left(\overline{\mathscr{A}}_{4}\right)$ & $\dot{S}\left(\overline{\mathscr{A}}_{5}\right)$ & Ranking \\
\hline PFHWA [19] & 0.385 & 0.571 & 0.275 & 0.480 & 0.405 & 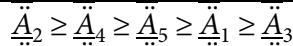 \\
\hline PFHWG [19] & 0.438 & 0.609 & 0.298 & 0.630 & 0.523 & $\underline{\ddot{A}}_{4} \geq \underline{\ddot{A}}_{2} \geq \underline{\ddot{A}}_{5} \geq \underline{\ddot{A}}_{3} \geq \underline{\ddot{A}}_{1}$ \\
\hline PFWA [9] & 0.384 & 0.584 & 0.259 & 0.488 & 0.397 & $\underline{\ddot{A}}_{2} \geq \underline{\ddot{A}}_{4} \geq \underline{\ddot{A}}_{5} \geq \underline{\ddot{A}}_{1} \geq \underline{\ddot{A}}_{3}$ \\
\hline PFWG [9] & 0.420 & 0.439 & 0.248 & 0.397 & 0.383 & $\underline{\ddot{A}}_{2} \geq \underline{\ddot{A}}_{1} \geq \underline{\ddot{A}}_{4} \geq \underline{\ddot{A}}_{5} \geq \underline{\ddot{A}}_{3}$ \\
\hline PFDWA [12] & 0.413 & 0.641 & 0.251 & 0.521 & 0.394 & $\underline{\ddot{A}}_{2} \geq \underline{\ddot{A}}_{4} \geq \underline{\ddot{A}}_{1} \geq \underline{\ddot{A}}_{5} \geq \underline{\ddot{A}}_{3}$ \\
\hline PFDWG [12] & 0.317 & 0.366 & 0.249 & 0.346 & 0.382 & $\underline{\ddot{A}}_{5} \geq \underline{\ddot{A}}_{4} \geq \underline{\ddot{A}}_{3} \geq \underline{\ddot{A}}_{1} \geq \underline{\ddot{A}}_{3}$ \\
\hline PFMSM & 0.334 & 0.415 & 0.259 & 0.394 & 0.406 & $\underline{\ddot{A}}_{2} \geq \underline{A}_{5} \geq \underline{A}_{4} \geq \underline{A}_{1} \geq \underline{A}_{3}$ \\
\hline PFWMSM & 0.038 & 0.089 & 0.020 & 0.095 & 0.076 & $\underline{\ddot{A}}_{4} \geq \underline{A}_{2} \geq \ddot{A}_{4} \geq \ddot{A}_{1} \geq \ddot{A}_{3}$ \\
\hline PFDMSM & 0.411 & 0.547 & 0.274 & 0.496 & 0.420 & $\underline{\ddot{A}}_{2} \geq \underline{\ddot{A}}_{4} \geq \underline{\ddot{A}}_{1} \geq \underline{\ddot{A}}_{5} \geq \underline{\ddot{A}}_{3}$ \\
\hline PFWDMSM & 0.074 & 0.159 & 0.024 & 0.135 & 0.086 & $\ddot{A}_{2} \geq \ddot{A}_{4} \geq \ddot{A}_{3} \geq \ddot{A}_{1} \geq \ddot{A}_{3}$ \\
\hline IFMSM [30] & & & NA & & & Unable to specify \\
\hline PyFMSM [32] & & & NA & & & Unable to specify \\
\hline QROFMSM [34] & & & NA & & & Unable to specify \\
\hline
\end{tabular}

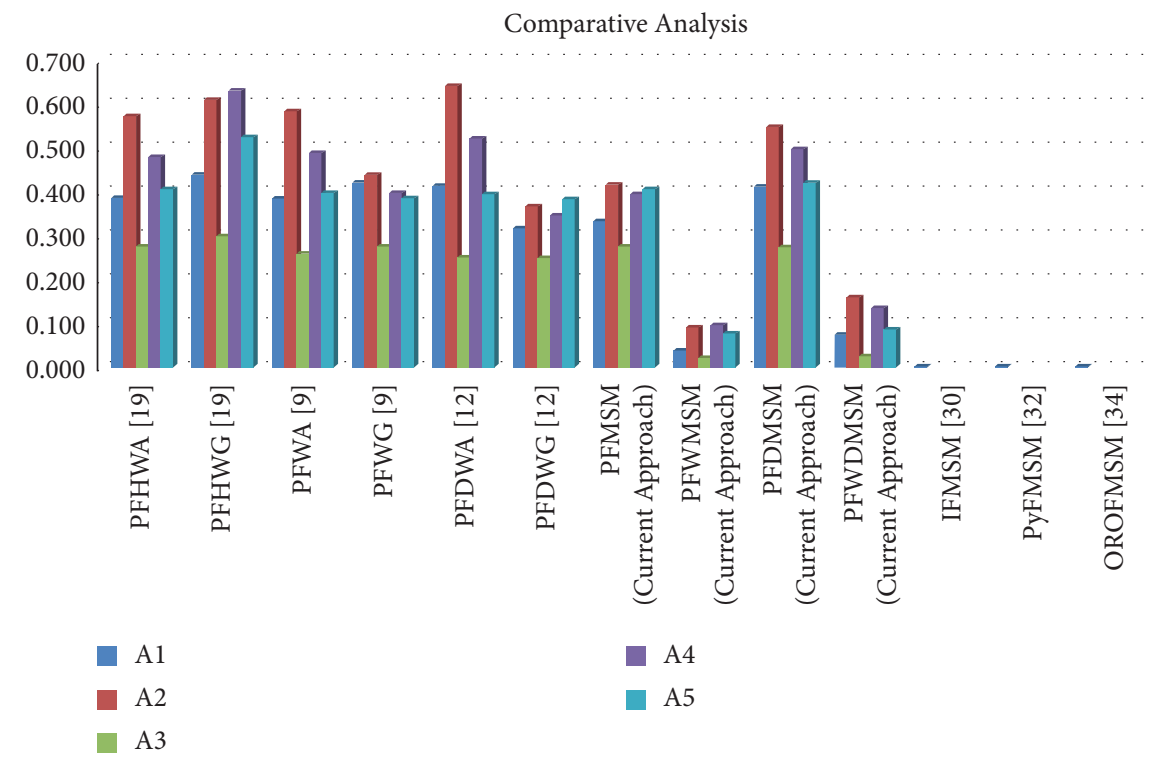

FIgURE 2: Comparative results obtained in Table 5 at a glance.

In the results of Table 5, we see that Hamacher AOs, Dombi AOs, and arithmetic and geometric AOs of PFSs provide us different results from the results obtained using the proposed approach. The reason behind this is that those operators do not take into account the interrelationship of the input arguments; however, the current MSM operators 
of PFNs do. The analysis also shows that the MSM operators or any other AOs of IFSs, PyFSs, and qROFSs are unable to deal with such kinds of advanced data. The reason behind the failure of previous work is the absence of the DA and the DR which leads to information loss. The reason behind the different results using the proposed approach is the incorporation of the relationship of the input argument and the absence of such a relationship in the traditional aggregation operators. For better understanding, a summary of the above-obtained results is depicted in Figure 2.

In Figure 2, the results of the comparative study section can be seen at once. It is clearly shown that the proposed MSM operators of PFSs can be used to investigate the MADM problems in a better way than the MSM operators of IFSs, PyFSs, and qROFSs.

\section{Conclusion}

In the manuscript, we proposed some MSM operators using picture fuzzy information. PFMSM operators have two main advantages. It uses four kinds of degrees, i.e., DM, DNM, DA, and DR to express the uncertain information as an expert's opinion for solving MADM problems. These operators take into account the relationship of more than two input values, unlike other traditional aggregation operators. The two characteristics make the notion of MSM of PFSs stronger than the previously discussed MSM operators. The MSM operators of PFSs can be used in MADM and multiattribute group decision making (MAGDM) efficiently as in the presented problem in Section 6. These types of MSM operators can further be improved if equipped with a parameter for enlarging the space of the DM, DA, DNM, and DR. Such work is aimed to be achieved in near future in the frame of interval-valued PFSs [5], SFSs, and TSFSs [42], interval-valued TSFSs [14], and complex TSFS [43]. The MSM operators upon combining with other Dombi t-norms, Einstein t-norms, and Frank $\mathrm{t}$-norms can also be some future work. The notion of TSFS can also be extended to introduce TSF matrices $[44,45]$ and to study their several aspects. Furthermore, such a concept can also be very beneficial when equipped with the frame of picture hesitant FS due to the ambiguous nature of uncertain information.

\section{Data Availability}

No data were used to support this study.

\section{Conflicts of Interest}

The author declares that there are no conflicts of interest.

\section{Acknowledgments}

The corresponding author is thankful to the office of Research, Innovation, and Commercialization (ORIC) of Riphah International University Lahore for supporting this research under the project: R-ORIC-21/FEAS-09.

\section{References}

[1] L. A. Zadeh, "Fuzzy sets," Information and Control, vol. 8, no. 3, pp. 338-353, 1965.

[2] K. T. Atanassov, "Intuitionistic fuzzy sets," Fuzzy Sets and Systems, vol. 20, no. 1, pp. 87-96, 1986.

[3] R. R. Yager, "Pythagorean fuzzy subsets," in Proceedings of the 2013 joint IFSA world congress and NAFIPS annual meeting (IFSA/NAFIPS), pp. 57-61, IEEE, Edmonton, AB, Canada, June 2013.

[4] R. R. Yager, "Generalized orthopair fuzzy sets," IEEE Transactions on Fuzzy Systems, vol. 25, no. 5, pp. 1222-1230, 2016.

[5] B. C. Cuong and V. Kreinovich, "Picture fuzzy sets," Journal of Computer Science and Cybernetics, vol. 30, no. 4, pp. 409-420, 2014.

[6] M. Ghaznavi, F. Soleimani, and N. Hoseinpoor, "Parametric analysis in fuzzy number linear programming problems," International Journal of Fuzzy Systems, vol. 18, no. 3, pp. 463-477, 2016.

[7] H. Jafari, M. T. Malinowski, and M. J. Ebadi, "Fuzzy stochastic differential equations driven by fractional Brownian motion," Advances in Difference Equations, vol. 2021, no. 1, pp. 1-17, 2021.

[8] Z. Zeshui Xu, "Intuitionistic fuzzy aggregation operators," IEEE Transactions on Fuzzy Systems, vol. 15, no. 6, pp. 1179-1187, 2007.

[9] H. Garg, "Some picture fuzzy aggregation operators and their applications to multicriteria decision-making," Arabian Journal for Science and Engineering, vol. 42, no. 12, pp. 5275-5290, 2017.

[10] W. Wang and X. Liu, "Intuitionistic fuzzy geometric aggregation operators based on Einstein operations," International Journal of Intelligent Systems, vol. 26, no. 11, pp. 1049-1075, 2011.

[11] D. Yu, "Some hesitant fuzzy information aggregation operators based on Einstein operational laws," International Journal of Intelligent Systems, vol. 29, no. 4, pp. 320-340, 2014.

[12] C. Jana, T. Senapati, M. Pal, and R. R. Yager, "Picture fuzzy Dombi aggregation operators: application to MADM process," Applied Soft Computing, vol. 74, pp. 99-109, 2019.

[13] Q. Khan, T. Mahmood, and K. Ullah, "Applications of improved spherical fuzzy Dombi aggregation operators in decision support system," Soft Computing, vol. 25, pp. 9097-9119, 2021.

[14] K. Ullah, H. Garg, Z. Gul, T. Mahmood, Q. Khan, and Z. Ali, "Interval valued T-spherical fuzzy information aggregation based on Dombi t-norm and Dombi t-conorm for multiattribute decision making problems," Symmetry, vol. 13, no. 6, p. 1053, 2021.

[15] X. Yu and Z. Xu, "Prioritized intuitionistic fuzzy aggregation operators," Information Fusion, vol. 14, no. 1, pp. 108-116, 2013.

[16] M. Riaz, D. Pamucar, H. M. Athar Farid, and M. R. Hashmi, "q-Rung orthopair fuzzy prioritized aggregation operators and their application towards green supplier chain management," Symmetry, vol. 12, no. 6, p. 976, 2020.

[17] T. Mahmood, M. S. Warraich, Z. Ali, and D. Pamucar, "Generalized MULTIMOORA method and Dombi prioritized weighted aggregation operators based on T-spherical fuzzy sets and their applications," International Journal of Intelligent Systems, vol. 36, no. 9, pp. 4659-4692, 2021.

[18] A. P. Darko and D. Liang, "Some q-rung orthopair fuzzy Hamacher aggregation operators and their application to 
multiple attribute group decision making with modified EDAS method," Engineering Applications of Artificial Intelligence, vol. 87, Article ID 103259, 2020.

[19] G. Wei, "Picture fuzzy Hamacher aggregation operators and their application to multiple attribute decision making," Fundamenta Informaticae, vol. 157, no. 3, pp. 271-320, 2018.

[20] G. Wei, M. Lu, and H. Gao, "Picture fuzzy heronian mean aggregation operators in multiple attribute decision making," International Journal of Knowledge-Based and Intelligent Engineering Systems, vol. 22, no. 3, pp. 167-175, 2018.

[21] Q. Khan, J. Gwak, M. Shahzad, and M. K. Alam, "A novel approached based on T-spherical fuzzy schweizer-sklar power heronian mean operator for evaluating water reuse applications under uncertainty," Sustainability, vol. 13, no. 13, p. $7108,2021$.

[22] F. Ateş and D. Akay, "Some picture fuzzy Bonferroni mean operators with their application to multicriteria decision making," International Journal of Intelligent Systems, vol. 35, no. 4, pp. 625-649, 2020.

[23] Z. Li, H. Gao, and G. Wei, "Methods for multiple attribute group decision making based on intuitionistic fuzzy Dombi Hamy mean operators," Symmetry, vol. 10, no. 11, p. 574, 2018.

[24] Z. Xu, "Approaches to multiple attribute group decision making based on intuitionistic fuzzy power aggregation operators," Knowledge-Based Systems, vol. 24, no. 6, pp. 749-760, 2011.

[25] Z. Mu, S. Zeng, and P. Wang, "Novel approach to multiattribute group decision-making based on interval-valued Pythagorean fuzzy power Maclaurin symmetric mean operator," Computers \& Industrial Engineering, vol. 155, Article ID 107049, 2021.

[26] I. Vinogradova, "Multi-attribute decision-making methods as a part of mathematical optimization," Mathematics, vol. 7, no. 10, p. $915,2019$.

[27] J. Liu, G. Long, and X. Xu, “A method of multi-attribute decision making based on basic point and weighting coefficients range," Procedia Computer Science, vol. 107, pp. 202205, 2017.

[28] C. Maclaurin, “A second letter to Martin Folkes, Esq.; concerning the roots of equations, with demonstration of other rules of algebra," Philosophical Transactions of the Royal Society of London,Series A, vol. 1729, no. 36, pp. 59-96, 1729.

[29] D. W. DeTemple and J. M. Robertson, "On generalized symmetric means of two variables," Publikacije Elektrotehnickog Fakulteta, Serija Matematika i Fizika, vol. 634/ 677, pp. 236-238, 1979.

[30] J. Qin and X. Liu, "An approach to intuitionistic fuzzy multiple attribute decision making based on Maclaurin symmetric mean operators," Journal of Intelligent and Fuzzy Systems, vol. 27, no. 5, pp. 2177-2190, 2014.

[31] P. Liu, S.-M. Chen, and Y. Wang, "Multiattribute group decision making based on intuitionistic fuzzy partitioned Maclaurin symmetric mean operators," Information Sciences, vol. 512, pp. 830-854, 2020.

[32] G. Wei and M. Lu, "Pythagorean fuzzy Maclaurin symmetric mean operators in multiple attribute decision making," International Journal of Intelligent Systems, vol. 33, no. 5, pp. 1043-1070, 2018.

[33] W. Yang and Y. Pang, "New Pythagorean fuzzy interaction Maclaurin symmetric mean operators and their application in multiple attribute decision making," IEEE Access, vol. 6, pp. 39241-39260, 2018.
[34] G. Wei, C. Wei, J. Wang, H. Gao, and Y. Wei, "Some q-rung orthopair fuzzy maclaurin symmetric mean operators and their applications to potential evaluation of emerging technology commercialization," International Journal of Intelligent Systems, vol. 34, no. 1, pp. 50-81, 2019.

[35] P. Liu, S. M. Chen, and P. Wang, "Multiple-attribute group decision-making based on q-rung orthopair fuzzy power maclaurin symmetric mean operators," IEEE Transactions on Systems, Man, and Cybernetics: Systems, vol. 50, no. 10, pp. 3741-3756, 2018.

[36] J. Wang, G. Wei, R. Wang et al., "Some q-rung interval-valued orthopair fuzzy Maclaurin symmetric mean operators and their applications to multiple attribute group decision making," International Journal of Intelligent Systems, vol. 34, no. 11, pp. 2769-2806, 2019.

[37] J. Qin, X. Liu, and W. Pedrycz, "Hesitant fuzzy Maclaurin symmetric mean operators and its application to multipleattribute decision making," International Journal of Fuzzy Systems, vol. 17, no. 4, pp. 509-520, 2015.

[38] P. Liu and X. Qin, "Maclaurin symmetric mean operators of linguistic intuitionistic fuzzy numbers and their application to multiple-attribute decision-making," Journal of Experimental \& Theoretical Artificial Intelligence, vol. 29, no. 6, pp. 11731202, 2017.

[39] J.-q. Wang, Y. Yang, and L. Li, "Multi-criteria decisionmaking method based on single-valued neutrosophic linguistic Maclaurin symmetric mean operators," Neural Computing \& Applications, vol. 30, no. 5, pp. 1529-1547, 2018.

[40] S.-M. Yu, H.-y. Zhang, and J.-q. Wang, "Hesitant fuzzy linguistic maclaurin symmetric mean operators and their applications to multi-criteria decision-making problem," International Journal of Intelligent Systems, vol. 33, no. 5, pp. 953-982, 2018.

[41] Y. Ju, X. Liu, and D. Ju, "Some new intuitionistic linguistic aggregation operators based on Maclaurin symmetric mean and their applications to multiple attribute group decision making," Soft Computing, vol. 20, no. 11, pp. 4521-4548, 2016.

[42] T. Mahmood, K. Ullah, Q. Khan, and N. Jan, "An approach toward decision-making and medical diagnosis problems using the concept of spherical fuzzy sets," Neural Computing \& Applications, vol. 31, no. 11, pp. 7041-7053, 2019.

[43] Z. Ali, T. Mahmood, and M.-S. Yang, "TOPSIS method based on complex spherical fuzzy sets with Bonferroni mean operators," Mathematics, vol. 8, no. 10, p. 1739, 2020.

[44] H. Farahani and M. J. Ebadi, "Finding fuzzy inverse matrix using Wu's method," Journal of Mahani Mathematical Research Center, vol. 10, no. 1, pp. 37-52, 2021.

[45] H. Farahani, M. J. Ebadi, and H. Jafari, "Finding inverse of a fuzzy matrix using eigen value method," International Journal of Innovative Technology and Exploring Engineering, vol. 9, no. 2, pp. 3030-3037, 2019. 